\title{
Process-induced bottom defects in clinch forming: simulation and effect on the structural integrity of single shear lap specimens
}

\author{
Coppieters S., Zhang H., Xu F.,Vandermeiren N., Breda A., \\ Debruyne D. ${ }^{\mathrm{a}, \mathrm{a}, \mathrm{a}, \mathrm{b}, \mathrm{a}, \mathrm{l}}$ \\ ${ }^{a}$ Department of Materials Engineering, KU Leuven, Campus Gent, Gebroeders De \\ Smetstraat 1, 9000 Gent, Belgium \\ ${ }^{b}$ Belgian Welding Institute, Technologiepark 935, 9052 Zwijnaarde, Belgium
}

\section{Abstract}

Lightweight and high strength sheet metal such as aluminium alloy sheets are used in a variety of industrial applications. Due to the limited weldability of these materials, mechanical joining techniques such as clinching are of interest. The challenge in this regard is that conventional round clinch forming locally induces large plastic deformations which potentially cannot be accommodated by materials with limited ductility. Ductile damage models are used to predict the occurrence of bottom cracks during conventional round clinch forming of EN AW-6082 T6 sheet. It is shown that cracks in the bottom of a clinched joint and the final static strength of a single lap shear specimen can be numerically reproduced provided that the post-necking strain hardening behavior and damage behavior of the base material are properly identified. The observed bottom cracks did not have a detrimental effect on the static strength and fatigue life of single shear lap specimens. It is hypothesised that fatigue cracks in single shear lap tests initiate due to fretting.

Keywords: Clinching, Damage, Process-induced defects, Limited ductility, 
Clinch forming, fatigue life

\section{Nomenclature}

\begin{tabular}{|c|c|}
\hline$A_{80}$ & Elongation at break \\
\hline$\sigma_{0.2}$ & Proof stress \\
\hline$\sigma_{U T S}$ & Ultimate tensile strength \\
\hline$K_{b h}$ & Stiffness blank holder \\
\hline$X$ & Bottom thickness \\
\hline$t_{n}$ & Neck thickness \\
\hline$t_{u}$ & Interlock \\
\hline$\mu_{i}$ & Coulomb friction coefficient \\
\hline$\sigma_{y}$ & Yield stress \\
\hline$\tau_{\max }$ & Shear stress limit \\
\hline$\sigma_{r e f}$ & Equivalent stress \\
\hline$K$ & Strength coefficient \\
\hline$\epsilon_{0}$ & Pre-strain \\
\hline$\epsilon_{e q}^{p l}$ & Plastic equivalent strain \\
\hline$n$ & Strain hardening exponent \\
\hline$\dot{\epsilon}$ & von Mises strain rate \\
\hline$m$ & Strain rate sensitivity \\
\hline$r$ & Lankford ratio \\
\hline$\epsilon_{\max }$ & Maximum uniform strain \\
\hline$\sigma_{\max }$ & Equivalent stress at maximum uniform strain \\
\hline$\epsilon_{R}$ & Fracture strain \\
\hline
\end{tabular}




$\begin{array}{ll}\sigma_{1} & \text { Maximum principal stress } \\ \sigma_{e q} & \text { Equivalent stress } \\ \sigma_{H} & \text { Hydrostatic stress } \\ f_{0} & \text { Initial void volume fraction } \\ k_{\omega} & \text { Shear damage parameter } \\ f_{c} & \text { Critical void volume fraction } \\ f_{g} & \text { Void volume fraction in the bottom of the clinched joint } \\ f_{n} & \text { Void volume fraction in the neck of the clinched joint } \\ L_{0} & \text { Initial gauge length extensometer } \\ R & \text { Force ratio in cyclic single shear lap testing }\end{array}$

\section{Introduction}

Materials with high specific strength (lightweight and high strength) but with limited ductility have entered a variety of industrial applications. For example, the use of aluminum alloy sheets and die castings has increased significantly in automotive applications [1]. Due to the limited weldability, joining these materials by mechanical joining techniques such as clinching is of interest. The basic principle of clinch forming processes is to create an interlock between the combining thin metal parts with the aid of relatively simple tools like a punch, a blank holder and a die [2]. The punch locally pushes metal into the die and, depending on the shape of these clinching tools, the resulting metal flow targets the creation of a permanent mechanical interlock. Depending on the application rectangular or round clinching tools are used. Materials with limited ductility, however, are conventionally 


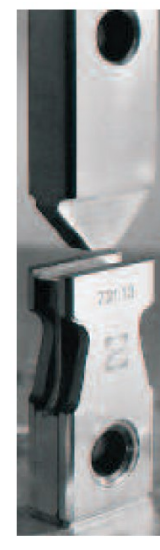

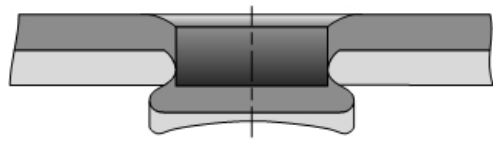

B

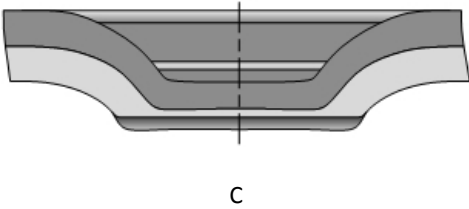

A

Figure 1: A. Rectangular clinching tools B. Cross-section front view C. Cross-section side view

clinched using rectangular clinching tools [3] which partially shear the sheets forcing the top sheet through slits at the bottom sheet, see Fig. 1. As such, shear clinching technology [4] yields a joint with sharp edges which have a detrimental effect on the fatigue life of the joint [5]. Additionally, the perforated sheets are prone to corrosion. For these reasons, conventional round clinching are usually preferred in industry yielding symmetrical load-bearing joints with a superior fatigue strength [3].

The challenge in this regard, however, is that conventional round clinch forming locally induces very large plastic deformations which can cause ductile fracture and cracks [6], significant local microstructural changes [7] and characteristic residual stress fields [8]. Obviously, these effects could potentially affect the in service structural integrity of the joint. 
Since clinching solely relies on plastic deformation of the base materials, a certain amount of ductility is required for obtaining defect-free joints. Early assessment of clinchability for materials was based on a 180 degrees bending test with zero radius [9]. Varis [10] formulated guidelines to assess the clinchability of materials as function of material parameters. Based on the available data on conventional clinching of high strength steels in 1998, Varis found that materials can be clinched provided that the elongation at break $A_{80} \geq 10 \%$ and the proof stress $\sigma_{0.2}<550 \mathrm{MPa}$. A more recent guideline [11], however, recommends to consider both the elongation at break $A_{80} \geq 8 \%$ and the strength-related metric $\frac{\sigma_{0.2}}{\sigma_{U T S}} \leq 0.7$. The latter ratio of proof stress to ultimate tensile strength enables to include the effect of strain hardening of the base material. The implication of these guidelines on commercial available aluminum alloys can be visualized using a so-called Ashby-diagram [12], see Fig.2. Each bubble in this chart represents a member of the alumimum alloy family (here 279 records). The vertical axis shows the elongation at break $A_{80}$ (i.e. a ductility metric) and the horizontal axis shows the strength-related metric $\frac{\sigma_{0.2}}{\sigma_{U T S}}$. The guidelines for clinchability [11] are shown in this chart as black solid lines dividing the chart in two distinct regions: good clinchability and process-induced defects. It can be seen from Fig. 2 that 62 (purple bubbles) out of 279 commercial available materials can clinched without generating forming defects. High strength aluminum alloys are clearly prone to process-induced defects in clinch forming.

In this paper clinch forming of EN-AW 6082-T6 is under investigation. The material is labelled in Fig.2 showing that it is prone to process-induced defects. The latter is confirmed in a recent study of Lambiase and Di Illio 


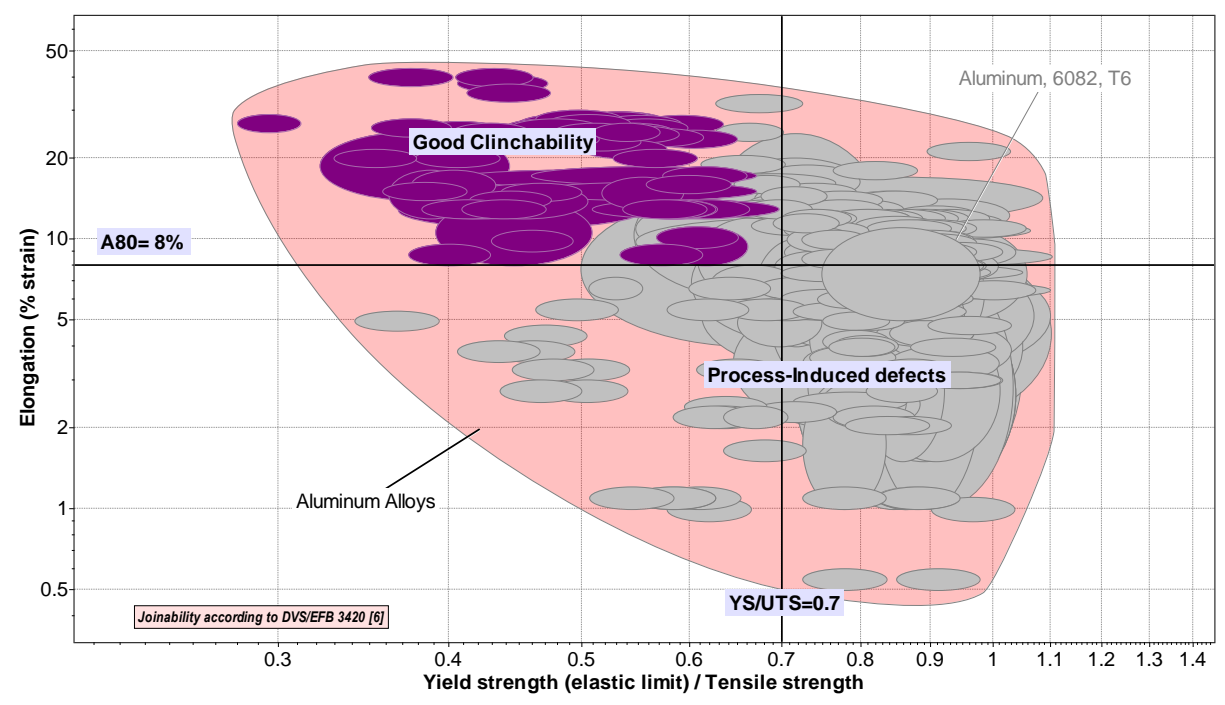

Figure 2: Clinchability of aluminum alloys according to [11]

$[6]$.

The most obvious solution for this problem is to increase the ductility of the base material by proper heat treatment or thermally supported clinch forming. Various methods have been proposed for heating up the substrates $[13,14,15]$. The option of heating up the tools is investigated by Hübner [14]. Hahn et al.[13] proposed an alternative method based on electromagnetic induction. He et al. [15] used flame heating to increase clinchability of titanium alloys. Recently Zhang et al. [16] investigated the effects of post-heat treatments (annealing and quenching) on the fatigue performance of clinched titanium alloy joints. Lambiase [17] recently showed that EN-AW 6082-T6 sheet can be clinched without the formation of cracks if the material is pre-heated adequately. Obviously, specific (local) heat treatments or thermally supported clinching complicate the manufacturing sequence resulting 
in higher costs and therefore cold clinching is usually preferred in industry.

A second solution to avoid process-induced defects is by modifying the geometry of conventional clinching tools. Such adaptive design is usually driven by numerical simulations. The majority of the published work on numerical simlation of clinched joints, however, deals with study of the joint quality (i.e. shape and interlock) $[18,19]$ and the associated final quasi-static strength [20, 21, 22, 23, 24]. Obviously, these studies are important to understand the impact of the clinching tools on the metal flow and the resulting interlock and neck thickness, and, consequently the final strength of the joint. Less attention, however, went to numerical optimization of clinching tools to avoid specific process-induced clinch forming defects. Neugebauer et al. [25] proposed dieless clinching to minimize crack-inducing tensile stresses. Abe et al. [26] modified a conventional clinching die with the aid of finite element techniques to obtain a defect-free joint between high strength steel and aluminum alloy sheet. Behrens et al. [27] used Oyane's damage criterion to optimize clinching tools and minimize damage in die cast aluminum alloy. Lambiase et al. [28] found that shallow dies and punches with smoother fillet radii enable to prevent cracks during clinching of aluminium alloys. A recent study of Lambiase [6] aimed at acquiring an improved understanding of the conditions causing process-induced defects in conventional clinch forming of materials with limited ductility. Lambiase inversely calibrated Rice and Tracey's damage model based on a punch-out test and used an FE model to predict process-induced defects in AW-EN 6082-T6 sheet. It was shown that this approach enables to predict neck failure as well as bottom defects (see Fig.3). Since neck fracture after clinch forming is unacceptable in terms of 

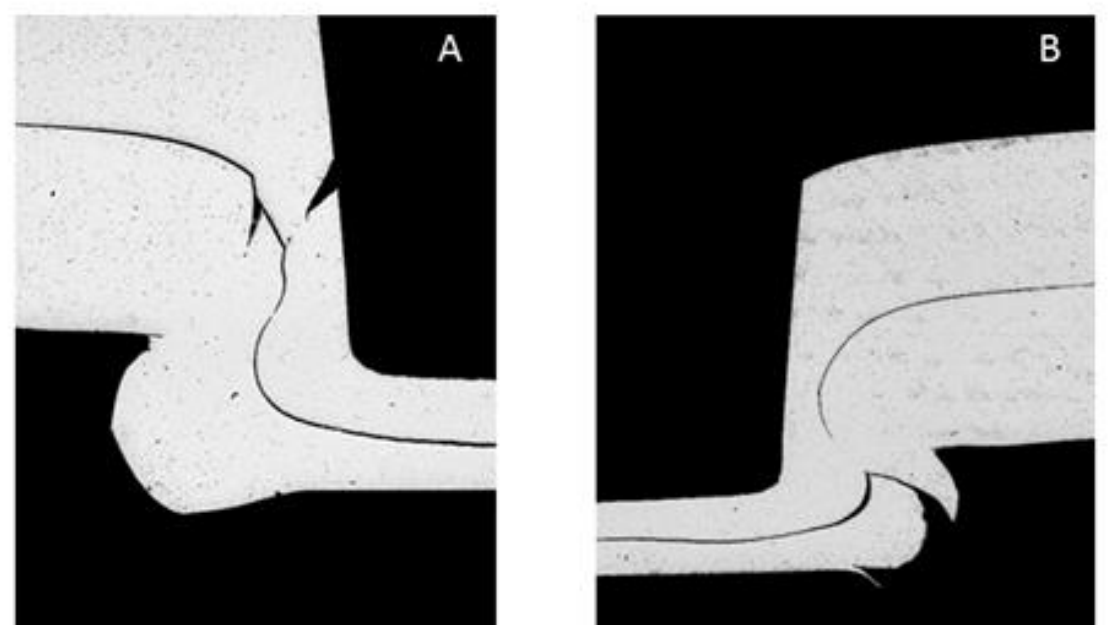

Figure 3: Process-induced defects. A) Neck fracture B) Bottom defect

structural integrity of the joint in service, present study is confined to bottom defects as shown in panel B of Fig.3. The focus in the first part of this paper is on the predictive accuracy of different ductile damage models to simulate process-induced bottom cracks in AW-EN 6082-T6 sheet.

Carboni et al.[29] investigated the fatigue failure behaviour of clinched single shear lap specimens and found that the applied force ratio $\mathrm{R}$ determines the failure mode. Mori et al. [30] found that the fatigue cross-tension test yields a smaller fatigue strength than the fatigue tension-shearing test. $\mathrm{Su}$ et al. [31] found that the fatigue failure mode of single shear lap specimens is different for low and high cycle loading conditions. In the second part of this paper the effect of bottom cracks in clinched joints on the static strength and the fatigue life of single shear lap specimens is scrutinized. 


\section{Materials and methods}

\subsection{Clinch forming}

\subsubsection{Experimental}

This study is confined to the so-called non-cutting round clinch process using a closed die. The die exhibits a groove contributing to the creation of the mechanical interlock. The right panel of Fig.4 shows the characteristic dimensions of the clinching tools: punch diameter, punch radius, die contour diameter, die contour depth and groove channel depth. The blank holder had a stiffness of $626 \frac{\mathrm{N}}{\mathrm{mm}}$. A press with a capacity of $150 \mathrm{kN}$ was used to manufacture the joints. High pressure grease was applied between the punch and upper sheet to enhance release ease. The machine was equipped to measure the punch force and punch stroke during clinch forming. The left panel of figure 4 show the cross section of the joint under investigation. A bottom thickness of $0.64 \mathrm{~mm}$ and a neck thickness of $0.35 \mathrm{~mm}$ were found. The minimum sheet thickness was not smaller than $0.1 \mathrm{~mm}$.

In round clinching neck failure can usually be avoided by limiting the die depth [28]. Once the radial metal flow is initiated, however, the material can expand freely in the die groove. At this stage, the material is subjected to high tensile stresses, and, consequently the material is prone to processinduced defects such as cracks. Figure 5 shows bottom defects visualized using a SEM image of the bottom of the joint. Two types of cracks can be distinguished depending on their occurrence during clinching forming. Type I cracks (indicated in red) are defined as early cracks which can potentially be closed at the end of the process, see micrograph $A A$ in Figure 5. It is hypothesised that Type II cracks (purple) occur later in the process and 

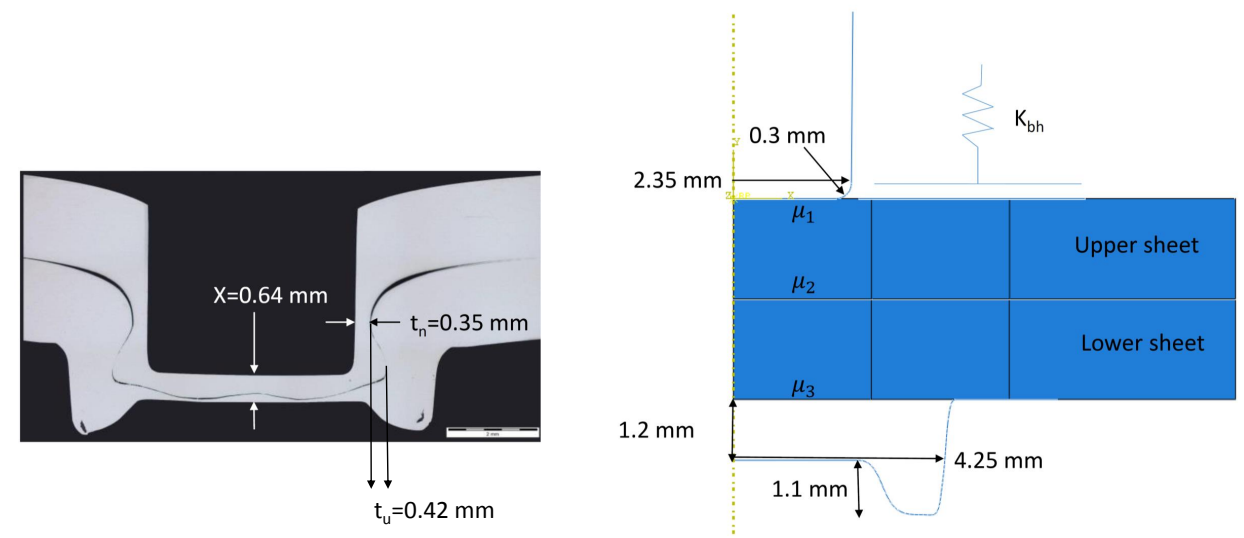

Figure 4: Clinching tools and cross section.

remain at the surface. SEM analysis, however, clearly shows that all observed crack-types involve ductile fracture due to overload.

\subsubsection{Numerical}

The geometry of the clinching tools was measured using a 3D optical profilometer. These measurements were used to create discrete rigids. All simulations were carried out using the commercial FEA code Abaqus/Explicit which assumes a hypoelastic-plastic constitutive model. Lagrangian adaptive mesh domains were created. An appropriate time scaling factor between 50 and 100 could be introduced without degradation of the calculated results. A displacement-driven axisymmetric FE model was used to simulate the clinch forming process. In this type of simulation the die is fixed while the punch undergoes a displacement during the simulation. The spring in 


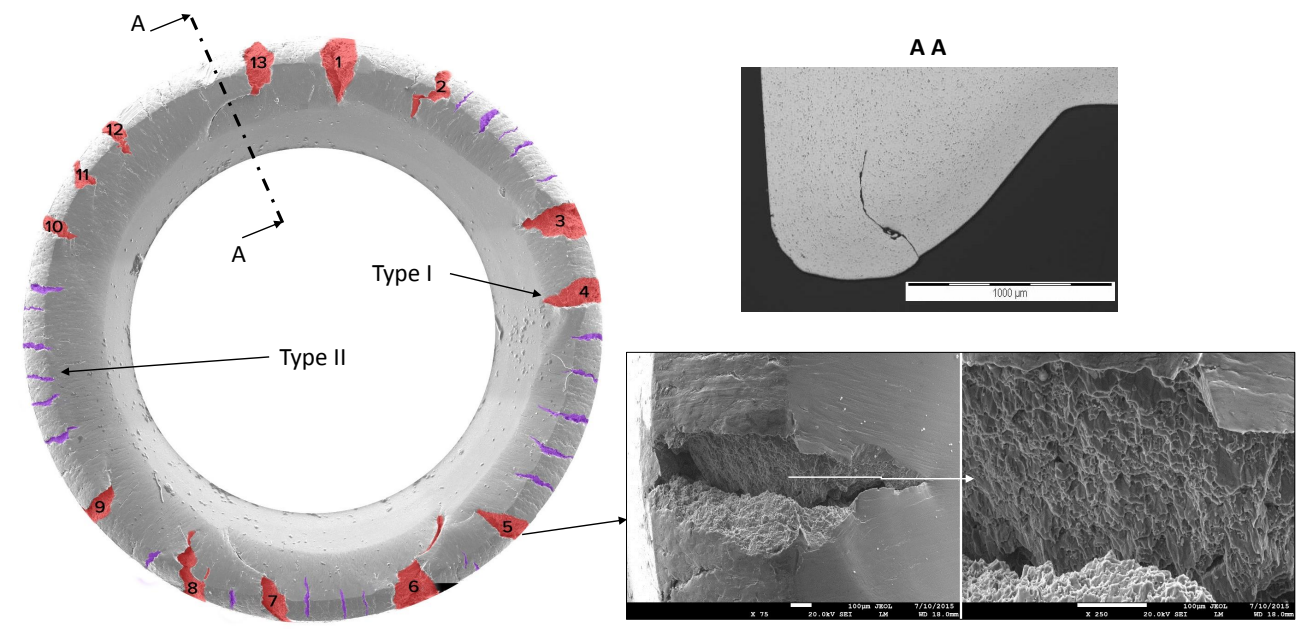

Figure 5: Process-induced bottom defects.

the blank holder is ignored. Instead, the blank holder is subjected to a small displacement $(0.05 \mathrm{~mm})$ downwards to mimic the blank holder force. All axisymmetric models were meshed using four-node bilinear rectangular elements using reduced integration and enhanced hourglassing control.

Three different frictional conditions are assumed (see figure 4) in the model: punch/blank holder-upper sheet contact $\mu_{1}$, the sheet-sheet interface contact $\mu_{2}$ and the die-lower sheet contact $\mu_{3}$. In this study, all contact surfaces are modelled using the Coulomb friction model and the values reported in section 2.2.2 are used. Since clinch forming involves high contact pressures the model was extended with a shear stress limit $\tau_{\max }=\frac{\sigma_{y}}{\sqrt{3}}[2]$. 
Table 1: R-values

\begin{tabular}{lll}
$r_{0}$ & $r_{45}$ & $r_{90}$ \\
\hline 0.519 & 0.722 & 0.416 \\
\hline
\end{tabular}

\subsection{Material Characterization}

Aluminum alloy AW-EN 6082-T6 with an initial thickness of $2 \mathrm{~mm}$ is used in this study. The material exhibits a high strength and is mainly used in automotive industry [1]. Standard tensile tests in the rolling direction (RD) were conducted to identify the pre-necking strain hardening behaviour. A regular tensile machine with a load capacity of $10 \mathrm{kN}$ was used. The crosshead speed was constant $(2 \mathrm{~mm} / \mathrm{min})$. The elongation was measured using a standard extensometer. The true stess-true plastic strain data (see Fig. 6) up to maximum uniform strain $\epsilon_{\max }$ was used to fit Swift's hardening law:

$$
\sigma_{r e f}=K\left(\epsilon_{0}+\epsilon_{e q}^{p l}\right)^{n}
$$

The parameters (labelled EM Swift) can be found in table 2. The strain rate sensitivity of the material was identified by conducting tensile tests (RD) at different cross head speeds $(2 \mathrm{~mm} / \mathrm{min}$ and $60 \mathrm{~mm} / \mathrm{min})$. Strain rate dependency was modelled as:

$$
\sigma\left(\epsilon_{e q}^{p l}, \dot{\epsilon}\right)=\sigma_{r e f}\left(\epsilon_{e q}^{p l}\right)\left(\frac{\dot{\epsilon}}{\dot{\epsilon}_{r e f}}\right)^{m}
$$

With $\sigma_{r e f}$ the reference hardening curve obtained from a tensile test (RD) conducted at a reference strain rate $\dot{\epsilon}_{r e f}=10^{-5} \frac{1}{s}$. The exponent $\mathrm{m}$ is calibrated based on a tensile test conducted at $60 \mathrm{~mm} / \mathrm{min}\left(\dot{\epsilon}=10^{-2} \frac{1}{s}\right)$ and a value of $\mathrm{m}=0.0035$ was found. The $\mathrm{r}$-values can be found in table 1 . 


\subsubsection{Post-necking strain hardening behavior}

The post-necking hardening behavior is scrutinized using a uniaxial compression test on a stack of circular disks, the post-necking tensile experiment (PNTE) and a Finite Element Model Updating (FEMU) approach.

The compression test is referred to as a Multi-layered Upsetting Test (MLUT) [2] and basically consists of the simultaneous application of two identical anvils to a number of stacked circular sheet metal specimens. The force-displacement data measured during the test can be used to identify the strain hardening behavior provided that the friction condition is known or can be ignored. It is important to note that this test mimics the balanced biaxial tensile test. All compression experiments in this study were conducted on a regular tensile machine with a load capacity of $250 \mathrm{kN}$ under quasi-static conditions. A stack with an initial diameter of $10 \mathrm{~mm}$ a stack ratio of 1 (i.e. 5 disks) was used. The material is assumed to be plastically isotropic which implies that stacking orientation with respect to the principal material axes can be ignored [2]. The anvils were adequately lubricated enabling to ignore friction. The procedure presented by Coppieters [2] and Steglich et al. [32] was used to retrieve the strain hardening behavior. Subsequently, Swift's hardening law Eq.(1) was fitted to the available data up to 0.5 true plastic strain.

The PNTE $[33,34]$ requires the input of the strain field in the diffuse neck. The latter was measured using stereo DIC [35] during a quasi-static tensile test in the RD. The method to retrieve the post-necking strain hardening from this experiment relies on the minimization of the internal and the external work. The method was used to identify Swift's hardening law up to 
Table 2: Swift's hardening parameters

\begin{tabular}{llll}
\hline Method & $K(M P a)$ & $\epsilon_{0}$ & $\mathrm{n}$ \\
\hline EM & 504 & 0.0221 & 0.15 \\
MLUT & 452.6 & 0.00366 & 0.092 \\
PNTE & 467.9 & 0.00789 & 0.114 \\
\hline
\end{tabular}

Table 3: Voce-Xue hardening parameters

\begin{tabular}{lllllll}
\hline Method & $\mathrm{A}$ & $\mathrm{B}$ & $\mathrm{C}$ & $\epsilon_{\max }$ & $\sigma_{\max }$ & $\mathrm{n}$ \\
\hline FEMU & 398.6 & 289.3 & 12.7 & 0.104 & 369.9 & 0.164 \\
\hline
\end{tabular}

a true plastic strain of about 0.5 .

Figure 6 shows the identified post-necking strain hardening behavior. Since both the MLUT and the PNTE yield experimental data up to a true plastic strain of 0.5 , data beyond this value is obtained by extrapolation using the identified phenomenological Swift law. Figure 6 also shows the extrapolated pre-necking strain hardening data (referred to as EM Swift). The latter approach is in the remainder of this work referred to as Extrapolation Method (EM). It can be seen that the MLUT and the PNTE yield similar results. Both identified hardening curves exhibit less strain hardening in the post-necking regime than the EM. It must be noted, however, that the PNTE reproduces the pre-necking strain hardening regime (i.e. up to $\epsilon_{\max }$ ) more accurately than the MLUT. Obviously, this can be explained by the fact that the MLUT probes a different stress state than uniaxial tension while the material exhibits plastic anisotropy.

Studies on ductile fracture often resort to the FEMU technique to identify the post-necking strain hardening behavior through a standard tensile test 
[36]. The assumption is that damage plays not a significant role until the development of the neck is quite advanced. The FEMU technique relies on the minimization of the discrepancy of the computed and measured tensile force to retrieve the post-necking hardening behaviour. Panel A, Fig.7 shows the prediction of the load-elongation curve using the identified strain hardening laws PNTE Swift and MLUT Swift. It can be inferred that none of the latter strain hardening laws enables to predict the tail of the experimentally obtained load-displacement curves. Good agreement between the simulation and the experiment can be only achieved by significantly increasing the strain hardening in the post-necking region. As suggested by Xue et al. [36], this can be done by modifying the post-necking strain hardening behavior:

$$
\sigma_{e q}= \begin{cases}A-(A-B) e^{-C \epsilon_{e q}^{p l}} & \text { if } \epsilon_{e q}^{p l} \leq \epsilon_{\max } \\ \sigma_{\max }\left(\frac{\epsilon_{e q}^{p l}}{\epsilon_{\max }}\right)^{n} & \text { if } \epsilon_{e q}^{p l}>\epsilon_{\max }\end{cases}
$$

Where $\sigma_{\max }$ is the true stress at the maximum uniform strain $\epsilon_{\max }$. By adjusting $\mathrm{n}$, the gap between the experiment and the simulation (labeled FEMU Voce-Xue in Panel A of Fig.7) can be closed. The FEMU Voce-Xue hardening parameters are summarized in table 3 . The corresponding hardening behavior (labeled FEMU Voce-Xue) is shown in figure 6. Obviously, the latter strain hardening behavior is not in agreement with the earlier findings of the PNTE and the MLUT. The reason for this is that the simulation (see Panel A, Fig.7) ignores the strain rate effects within the diffuse neck. Panel B, Fig.7 shows the effect of strain rate dependency by using Eq.(2) for simulating the tensile test. Although the strain rate sensitivity of the material is small $(m=0.0035)$, it cannot be ignored if FEMU is used to identify the post-necking strain hardening behavior. 


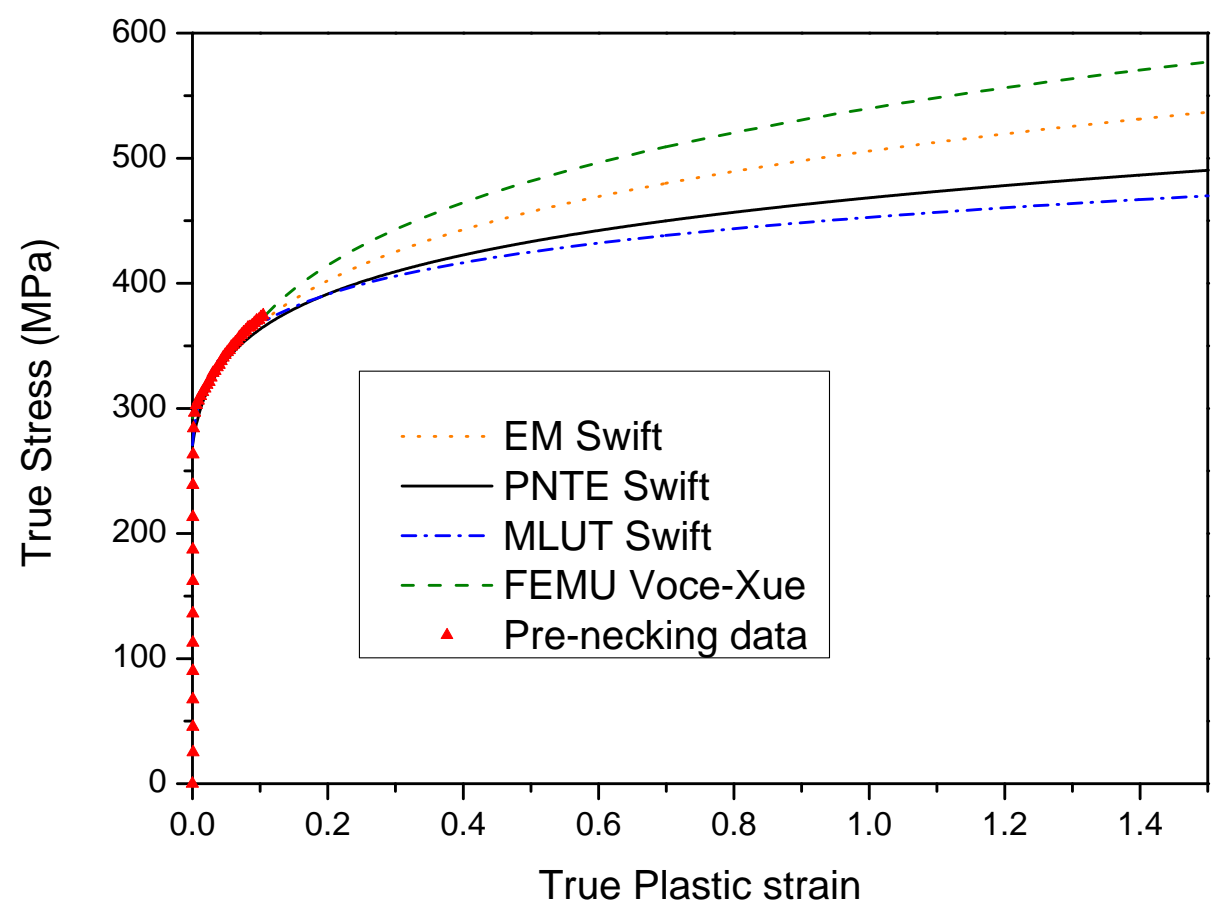

Figure 6: Identified post-necking strain hardening behavior up to true plastic strain of 0.5.

In conclusion, the hardening behavior of AW6082-T6 can be described by a Swift-type hardening law, i.e. no saturation occurs up to 0.5 true plastic strain. Although the PNTE and the MLUT yield very similar results, it can be concluded that PNTE Swift provides the best description of the strain hardening behavior. FE-based inverse calibration of the post-necking strain hardening behaviour using the tensile test requires the knowledge of the strain rate sensitivity. 


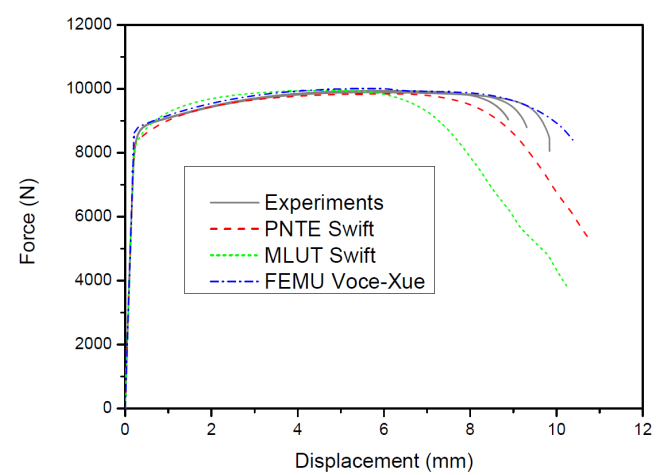

A

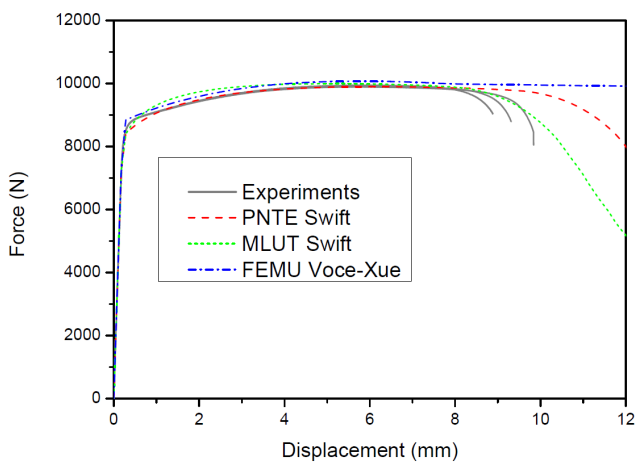

B

Figure 7: Numerical simulation of the tensile test (RD). A) Strain rate independent material behavior B) Strain rate dependent material behavior Eq.(2)

\subsubsection{Ductile damage}

Two ductile damage criteria are used in section 3 to analyze processinduced defects in the clinch forming process using an axisymmetric FE model. These type of models rely on the hypothesis that ductile failure will occur when the maximum damage of the material exceeds a critical damage value (CDV). Such criteria are usually in an integral form to account for the deformation history. Although such criteria are the result of post-processing stresses as a function of the deformation history, they have shown to be very useful in the analysis of processes involving plastic deformation of metals. In this study, the phenomenological Cockroft-Latham criterion [37] which predicts ductile failure in regions of the largest tensile stresses was adopted: 


$$
C D V_{C \& L}=\int_{0}^{\epsilon_{R}} \max \left(\frac{\sigma_{1}}{\sigma_{e q}}, 0\right) d \epsilon_{e q}
$$

With $\epsilon_{R}, \sigma_{1}$ and $\sigma_{e q}$ the fracture strain, the maximum principal stress and the equivalent von Mises stress, respectively. Lambiase and Di Illo [6], however, concluded from their study on 6082-T6 sheet that Rice and Tracey's (R\&T) criterion [38], which is a physics-based model, is an adequate criterion to predict cracks in clinch forming. As such, Rice and Traceys damage criterion was also adopted here:

$$
C D V_{R \& T}=\int_{0}^{\epsilon_{R}} e^{1.5 \frac{\sigma_{H}}{\sigma_{e q}}} d \epsilon_{e q}
$$

With $\sigma_{H}$ the hydrostatic stress. Both the C\&L and the R\&T are referred to as uncoupled models since plastic material response is decoupled from ductile damage and failure. The $C \& L$ and $R \& T$ criterion can be easily calibrated: only the critical damage variable (CDV) needs to be calibrated, preferably based on an experiment which resembles the clinching process. Lambiase [17] calibrated the $C D V_{R \& T}$ for 6082 T6 (thickness 1mm) using a punch-out test and found a value of $C D V_{R \& T}=0.6$. The punch-out test resembles a blanking operation which partly corresponds with the clinch forming process. In this study, the CDV was inversely calibrated using the FE model of the clinch forming process (details on the FE model can be found in section 2.1.2). To do so, however, the onset of cracks must be experimentally observed. The left panel of Fig.8 shows the cross-section of the joint under investigation with an bottom thickness of $\mathrm{X}=1.55 \mathrm{~mm}$. At this stage the first cracks in the bottom of the joint appear. Panels A and B show the numerical counterparts using the $R \& T$ and the $C \& L$ criterion, 
Table 4: CDV

\begin{tabular}{lll}
\hline Criterion & $R \& T$ & $C \& L$ \\
\hline $\mathrm{CDV}$ & 1.45 & 0.69 \\
\hline
\end{tabular}

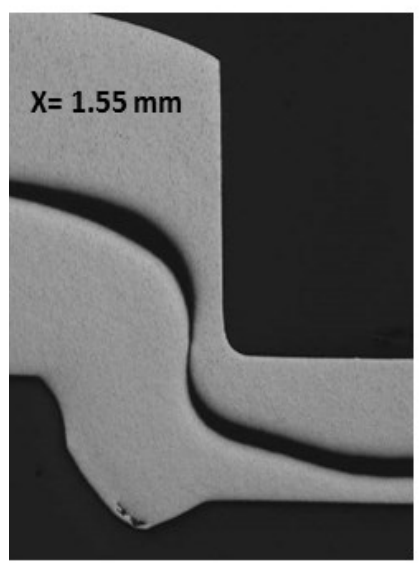

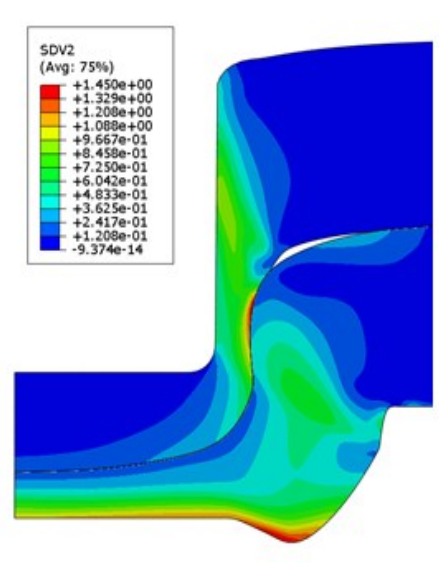

A

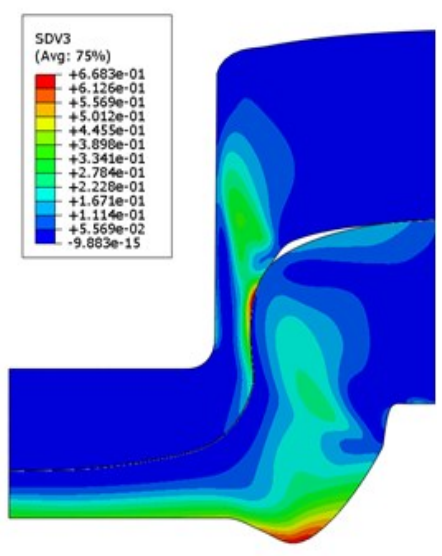

B

Figure 8: Inverse calibration of the Critical Damage Variable (CDV). A) Rice and Taylor B) Cockroft and Latham.

respectively. By comparing the experimental and numerical results, the CDV of both ductile damage criteria can be estimated and the results can be found in table 4 .

Unlike uncoupled models such as the $R \& T$ and the $C \& L$ criterion, coupled ductile damage models modify the plastic material response as a function of the accumulated damage. The Modified Rousselier (MR) model [39] is used in section 3 to analyze process-induced defects in clinch forming. The MR model enables to address shear ruptures as well as tension-dominated 
failures. Compared to uncoupled ductile fracture criteria, the calibration of the MR model entails significant experimental/numerical effort. Conventionally, an FE-based inverse method is used to calibrate the initial void volume fraction $f_{0}$ and the shear damage parameter $k_{\omega}$ using a notched tensile specimen and a shear test specimen, respectively. In this work, the calibration strategy outlined in $[39,24]$ was followed and the identified parameters (labelled Standard) are shown in table 5. The requirement, however, that the load-displacement curve of the notched tensile test is independent of $k_{\omega}$ could not be established, see Fig.9. Additionally, it was found that the strain rates in both experiments differ by a factor 10 . The latter issues potentially bias the identification of the damage parameters. Another concern is that the standard procedure uses sheet metal samples to calibrate the MR model. However, due to the small dimensions of the clinching tools, clinch forming must be regarded as a bulk forming problem. To cope with this issue, the damage parameters can be inversely identified from the clinch forming process itself. The latter requires information with respect to the onset and location of the cracks during clinch forming. Since this study is confined to bottom defects, the identification objective is quite simple: find the set of damage parameters $\left(f_{0}\right.$ and $\left.k_{\omega}\right)$ enabling to avoid fracture in the neck of the joint but promoting fracture in the bottom of the joint. The onset of fracture, however, at the bottom of the joint might also depend on the frictional condition between die and lower sheet. To scrutinize the importance of the interplay between damage parameters and frictional conditions (see figure 4) an orthogonal design was adopted. Six 5-level parameters are contained in the orthogonal array, see table 6 . Since high pressure grease was 
applied between punch and upper sheet, the frictional condition is assumed to be $\mu_{1}=0$. In addition, the critical void volume fraction was assumed to be equal to $f_{c}=0.2[24]$. Physically realistic values were chosen for the other parameters. The objective function $f_{g}$ in the orthogonal design is the void volume fraction in the bottom of the joint. Once this value reaches $f_{g}=f_{c}=0.2$, bottom defects can be expected. According to the orthogonal design, bottom fracture is promoted by the parameter set Orthogonal Design shown in table 5. This parameter set, however, yields a double fracture (bottom and neck) in the simulation indicating that this first order approach is probably not adequate since it ignores potential interaction effects. The orthogonal design merely shows that the prediction of process-induced defects depends on a complex interaction of materials properties as well as frictional conditions. By analysing all the simulations in the orthogonal design (in total 25) using the following objective function (to be maximized):

$$
g\left(f_{g}, f_{n}\right)=\left[1-\frac{f_{c}-f_{g}}{f_{c}}\right]+\left[1-\frac{f_{n}}{f_{c}}\right]
$$

a parameter set which avoids fracture in the neck and approaches onset of fracture in the bottom can be found. With $f_{n}$ the void volume fraction in the neck of the joint. The found parameter set is referred to as Best Fit in table 5. Small modifications of the parameter set, however, are required to enhance the predictive accuracy with respect to the shape and the onset of fracture. This can be achieved by modifying $\mu_{3}$ to 0.1 and slightly increasing $f_{0}$ to 0.009, respectively. The optimized parameter set, referred to as Optimized $(I M R)$, can be found in table 5. The evolution of the void volume fraction using the latter parameter set is shown in Fig.10. Indeed, $f_{g}$ exceeds 0.2 
Table 5: Modified Rousselier Model and frictional conditions of the tribological system in clinch forming. Rousselier constants defined as in [24].

\begin{tabular}{llllllll}
\hline Method & $\mu_{1}$ & $\mu_{2}$ & $\mu_{3}$ & $k_{\omega}$ & $f_{0}$ & $f_{c}$ & Fracture location \\
\hline Standard [24, 39] (MR) & 0 & 0.3 & 0.1 & 2 & 0.0008 & 0.2 & Neck \\
Orthogonal Design & 0 & 0.3 & 0.1 & 1.5 & 0.008 & 0.2 & Neck and Bottom \\
Best Fit & 0 & 0.4 & 0 & 0.5 & 0.008 & 0.2 & No Fracture \\
Optimized (IMR) & 0 & 0.4 & 0.1 & $0.5-1$ & 0.009 & 0.2 & Bottom \\
\hline
\end{tabular}

Table 6: Orthogonal Design: parameters and levels

\begin{tabular}{lllllll}
\hline Level & $\mu_{1}$ & $\mu_{2}$ & $\mu_{3}$ & $k_{\omega}$ & $f_{0}$ & $f_{c}$ \\
\hline 1 & 0 & 0 & 0 & 0.3 & 0.003 & 0.2 \\
2 & 0 & 0.1 & 0.1 & 0.5 & 0.005 & 0.2 \\
3 & 0 & 0.2 & 0.2 & 0.8 & 0.008 & 0.2 \\
4 & 0 & 0.3 & 0.3 & 1 & 0.0008 & 0.2 \\
5 & 0 & 0.4 & 0.4 & 1.5 & 0.0004 & 0.2 \\
\hline
\end{tabular}

while $f_{n}$ remains below 0.15 until the end of the process. 


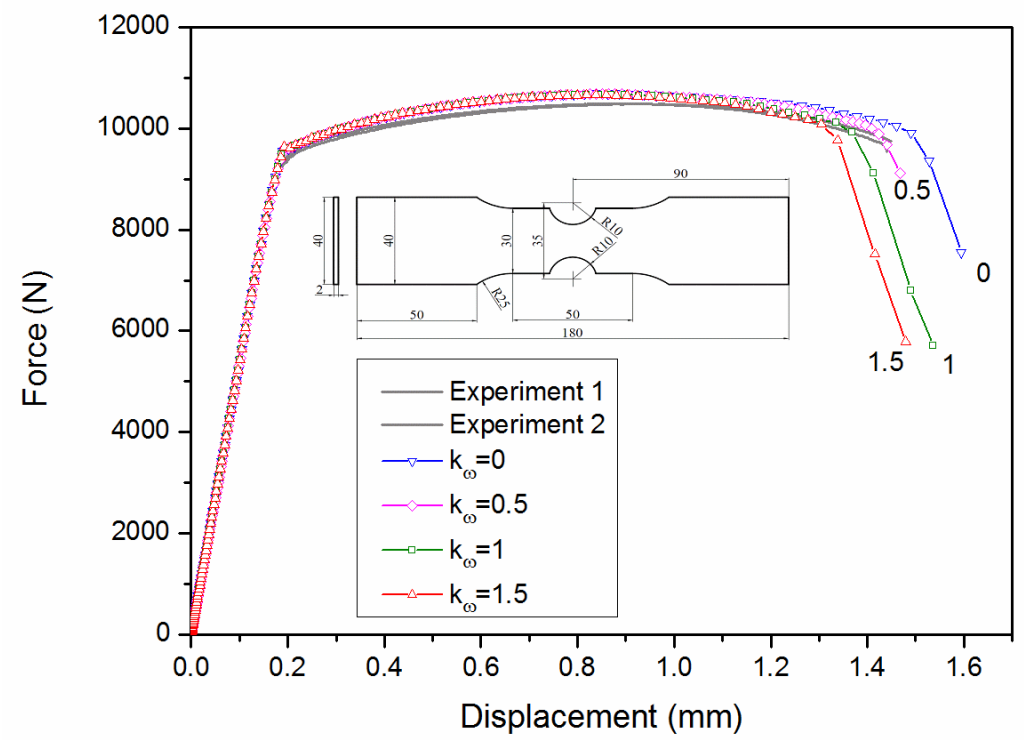

Figure 9: Influence of $k_{\omega}$ on the simulated notched tensile test.

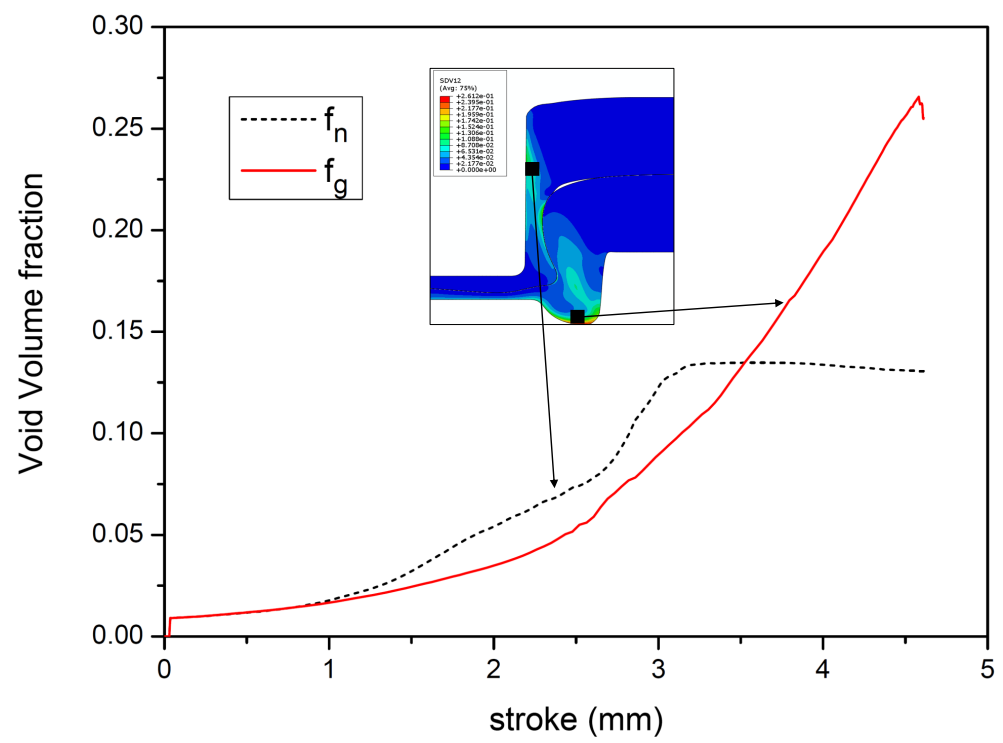

Figure 10: Evolution of the void volume fraction in the neck $f_{n}$ and in the groove of the die $f_{g}$ using IMR. 


\section{Numerical prediction of process-induced clinch forming defects}

The goal of this section is to scrutinize the predictive accuracy of different damage models: Cockroft \& Latham (C\&L) criterion, Rice \& Traceys (R\&T) criterion, Modified Rousselier Model (MR) and the Inversely calibrated Modified Rousselier Model (IMR). Those damage models are implemented in an axisymmetric FE model, see section 2.1.1. The strain hardening behavior

is described with PNTE Swift, see table 2. The assessment is based on the location and the onset of bottom cracks during clinching.

Figure 11 shows a cross-section (final bottom thickness $\mathrm{X}=0.64 \mathrm{~mm}$ ) along with numerical predictions using different ductile fracture criteria and the Modified Rousselier model (MR and IMR). It can be seen from Figure 11 that all models accurately reproduce the final shape of the joint. The contour of the joint and the interface between the connecting sheets is in good agreement with the experiment. The later indicates that the metal flow is simulated with sufficient accuracy.

The incomplete connection at the interface (see artefact $b$ shown in Figure 11 ) is predicted by all models. Since the FE model ignores the stripper mechanism, the artefact $c$ (slight bending of the surrounding material) could not be reproduced. It must be noted that observation $d$, i.e. the sharp transition caused by the local indentation of the punch, is not captured by the FE model.

The numerical predictions in Fig.11 show the damage variables for the adopted damage models. It can be inferred that the C\&L criterion and the R\&T criterion both predict a high probability of crack occurrence in the bottom of the joint. The only difference is that the R\&T criterion predicts po- 
tential cracks slightly earlier in the process than the C\&L criterion. Although crack propagation was not considered in the simulation, this numerical result seems to correspond with the experimental observation of type I and type II cracks, see section 2.1.1. If, however, the calibrated CDV values (see section 2.2) for both criteria are evaluated, neck fracture is also predicted which is clearly not in agreement with the experimental observations.

Figure 11 shows that the MR model failed to predict the correct crack location and promotes a strong neck rupture. The latter model was calibrated using the standard procedure. Although Zhao et al. [24] successfully used this approach to predict neck failure, it seems that it cannot predict the bottom cracks during clinch forming. Figure 11 shows that the IMR enables to reproduce the bottom defects. Unlike all other models, the IMR does not predict neck fracture. Indeed, the critical void volume fraction $\left(f_{c}=0.2\right)$ is only exceeded in the bottom of the joint. That means that both the onset and location are predicted accurately at the end of the process.

Figure 12 shows the validation of the FE model in terms of the process graph. A deviation between the numerically computed and experimentally obtained process graph can be noticed. These deviations might be attributed due to the assumptions concerning the FE model: infinitely rigid tools (clinching tools and press), a constant friction coefficient and strain rate independent material behavior. Given this, the numerically predicted process graph is deemed sufficiently accurate. 

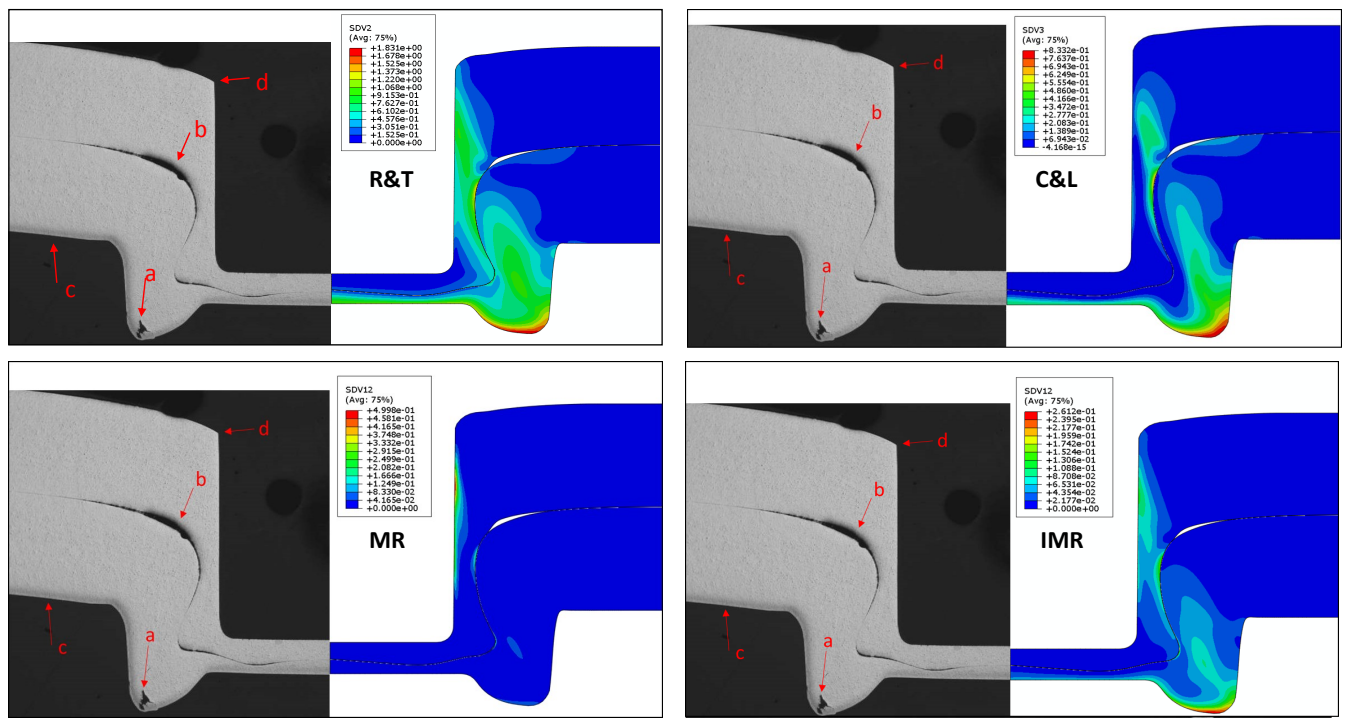

Figure 11: Numerical prediction of process-induced defects: R\&T, C\&L, MR and IMR.

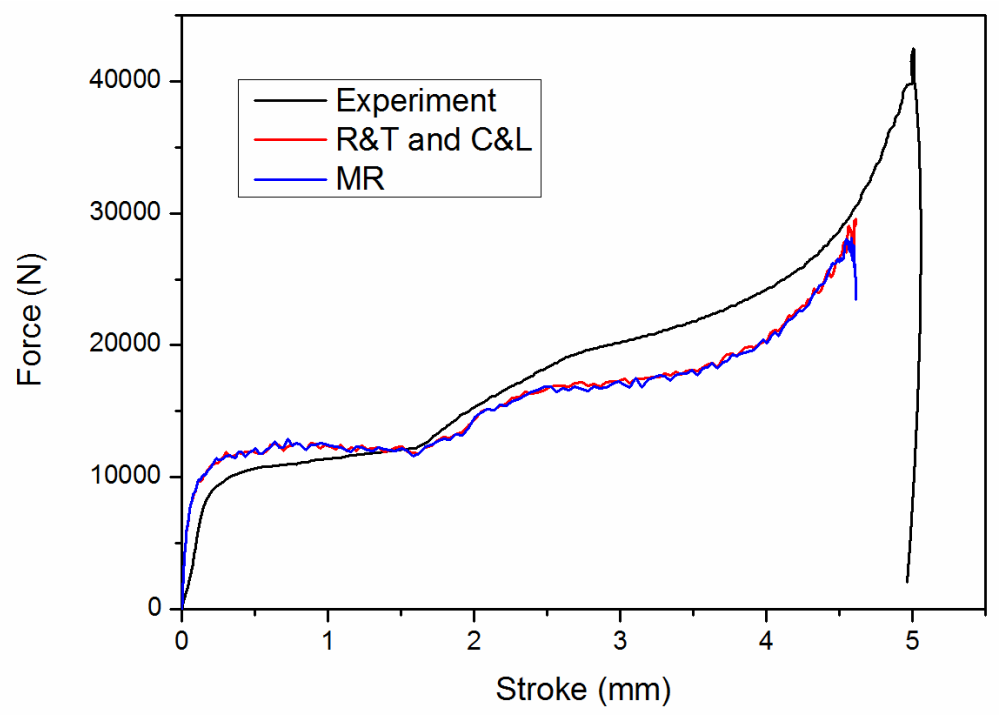

Figure 12: Process curve clinch forming operation. 


\section{Quasi-static and cyclic single lap shear tests.}

In this section, the static and fatigue strength of the clinched joint containing bottom defects (see section 2.1.1) is investigated through a single shear lap test. Due to its simplicity, the test is commonly adopted for the determination of the static shear strength of mechanical joints, e.g. [28, 40, 41, 42]. Likewise, the cyclic single shear lap test is often applied to determine the fatigue strength of the joint [29, 43, 30, 31]. The latter studies describe in detail the failure modes associated with the single shear lap test. It must be noted, however, that in practice a clinched joint is often subjected to a combination of shear and normal loads. Coppieters et al.[20] investigated the static multi-axial strength of clinched connections using a modified Arcan set up. Studies regarding the fatigue life of clinched joints under multi-axial loading are currently lacking in literature. The aim of this section is to study the influence of bottom cracks on the static and cyclic strength of single shear lap specimen and the associated failure mechanisms.

\subsection{Quasi-static shear lap tests}

The test conditions were in accordance with [44]. The specimen had a width of $45 \mathrm{~mm}$, an overlap of $18 \mathrm{~mm}$ and a free length of $95 \mathrm{~mm}$. The elongation was measured using an extensometer with $L_{0}=50 \mathrm{~mm}$. All experiments are conducted using a standard tensile machine with a load capacity of 10 $\mathrm{kN}$ using a cross head speed of $10 \mathrm{~mm} / \mathrm{min}$. The experiment was repeated 10 times and the results are shown in figure 13. An average maximum static shear strength of $2248 \mathrm{~N}$ was found and Panel A of Fig. 13 shows a typical failure mechanism exhibiting a pure neck fracture. Unbuttoning during 
the single shear lap test is prevented by the large interlock $\left(t_{U}=0.42 \mathrm{~mm}\right)$. Moreover, the static pull-out strength $(3150 \mathrm{~N})$ measured by the cross-tension test [2] was larger than the static shear strength (2248 N). The tested single shear lap specimens were investigated and no experimental evidence could be found indicating that bottom defects affect the static strength or the failure mechanism. Microscopic cross-section analysis after testing did not reveal any activation of bottom cracks. This could be expected since the static load in both the single shear lap test is transferred via the neck of the joint. Consequently, the observed bottom cracks do not play a role of importance during quasi-static loading of single shear lap specimens.

Finally, the experimental observations obtained in the single shear lap test are also reproduced with the aid of a 3D FE model. Solution variables after clinch forming are transferred to a second simulation step which embarks on the single shear lap test. Figure 13 shows the results of two simulations. Both simulations use the inversely calibrated Modified Rousellier Model (IMR). The red curve shown in Fig.13 is obtained by adopting the Voce-Xue hardening law, see section 2.2.1. Although the model captures the correct failure mode, failure is predicted as from a displacement of about 0.5 mm. Additionally, it can be inferred that this model largely overestimates the maximum strength. This result confirms that the Voce-Xue hardening law shown in Fig.6 overestimates the strain hardening in the post-necking regime. The PNTE Swift hardening law shown in figure 6 is deemed to describe a more realistic post-necking strain hardening behavior. The blue curve in Fig.13 is obtained with thew PNTE Swift and the IMR damage model. It can be seen that simulation predicts a failure load and displace- 


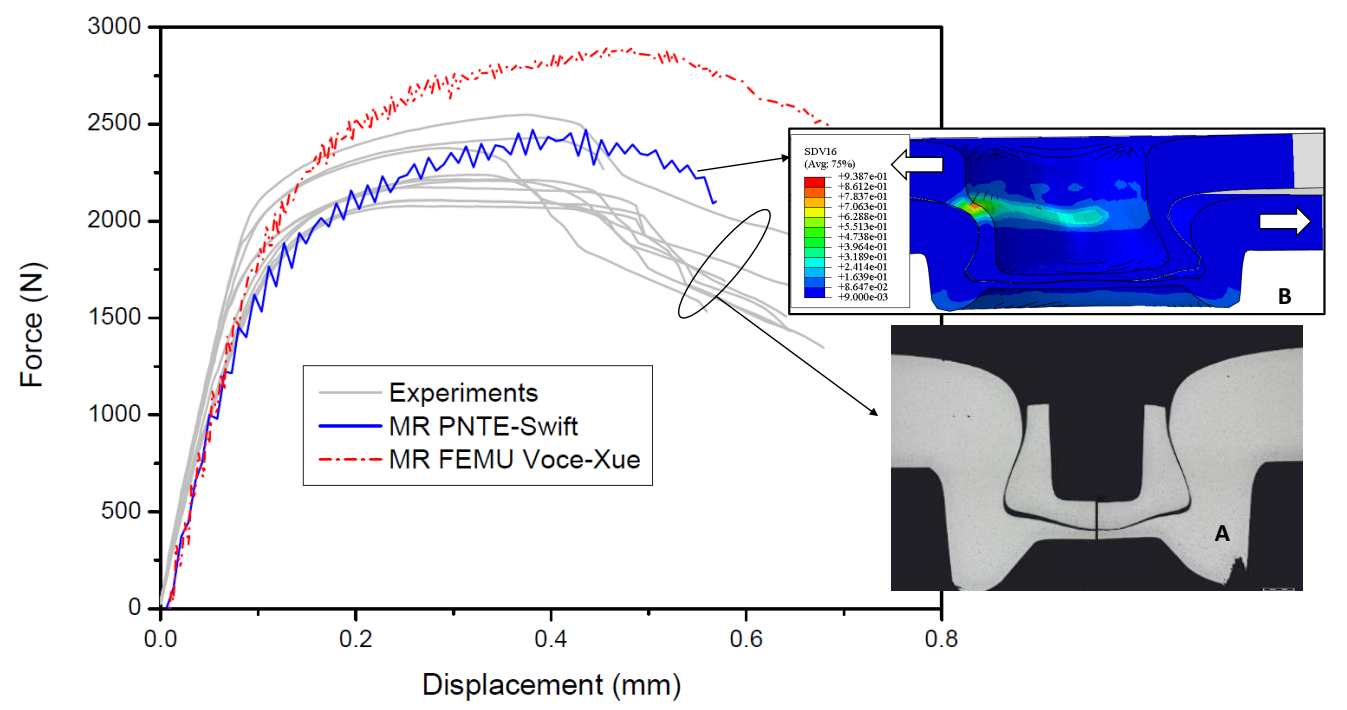

Figure 13: Single shear lap test: experiments and numerical prediction. A. Failure mode B. Numerical prediction

ment at break within in the experimental range. As such, the model can be used to generate reliable virtual data to calibrate equivalent models as proposed by Breda et al. [40]. In addition, Fig.13 illustrates the importance of the post-necking strain hardening behavior for simulating the quasi-static strength of a clinched joint in a shear lap configuration. Finally, it is clear from panel B, Fig.13 that the plastic deformation and damage localizes in the neck of the joint. The material state at the bottom defects, however, does not change during a single shear lap test. As such, the numerical results confirm that process-induced bottom defects have no detrimental effect in the quasi-static single shear lap test. 


\subsection{Cyclic shear lap tests}

As stated by Lambiase [17], bottom defects might have a detrimental effect on the fatigue life of a clinched joint containing process-induced bottom defects. The latter is partly scrutinized in this section: cyclic single shear lap tests were conducted on clinched joints exhibiting bottom defects. All specimens were subjected to a constant cyclic loading of $20 \mathrm{~Hz}$ on an Instron 8800 hydraulic testing machine. The force ratio, $\mathrm{R}$ was set to 0,1 and a maximum force not larger than the static yielding force was applied. The fatigue test was halted when either a displacement of $5 \mathrm{~mm}$ or a total amount of 2 million cycles was reached. Additionally, cyclic single shear lap tests were conducted on clinched joints of which the bottom defects were carefully removed by grinding and polishing. The latter experiment excludes potential fatigue crack initiation at the crack tip of a bottom defect. The failure mode of each test specimen was recorded and the failure modes were analysed. $\mathrm{Su}$ et al. [31] found that fatigue cracks in single shear lap specimens start from the curved interfacial surface of the upper sheet and then grow into the upper sheet. The latter results in neck rupture and upper-sheet separation for low and high cyclic testing, respectively. In this study, however, three failure modes are observed, see Fig. 14. Panel A shows a typical neck failure along with an indication (see black arrow) of fretting wear [15]. Panel B is a combined failure mode of joint and base material. Figure 15 reveals that the latter failure mode also involves fretting wear. Panel $\mathrm{C}$ of Figure 14 shows a complete failure of the base material. Inspection of the contacting

surfaces reveals fretting wear which corresponds to the initiation region, see Figure 16. Additionally, it can be inferred from 16, Panel B that the fatigue 
crack propagates outwards as indicated by the green arrows. Ductile fracture appears at locations where the material was connected just before complete separation of the sheets.

Although three failure modes were observed, it can be inferred from Fig.14 that the dominant failure mode is a combined failure of base material and joint (Panel B). Moreover, a clear relation between failure mode and low and high cyclic testing could not be established. For fatigue test specimens that failed both in the base material and clinched connection (Panel B), there is a possibility that the fatigue crack initiates at the crack tip of the initial bottom crack. Therefore, scanning electron microscopy (SEM) was performed at different locations (Figure 15 A, B and C) of the fractured surface.

From the more detailed SEM images shown in Figure 17, it can be seen that location $A$ exhibits a more brittle fracture tending to propagate from the right to the left, as indicated by the black arrow. The initial bottom crack is clearly visible at the SEM image of location $B$, but no solid evidence could be found that this initial crack acts as an initiation point for the fatigue crack. A ductile fracture is noticed at location $C$, where the dimples from an overload are clearly visible. This suggests that before failure of the fatigue test specimen, the last connection between the two fractured surfaces was at location $C$. An exact initiation point, however, of the fatigue crack could not be found as the fracture had a more brittle character and no clear beach marks were found.

Furthermore, it can be concluded from Fig.14 that the fatigue lifetime of shear lap specimen did not improve by removing the bottom cracks. The 


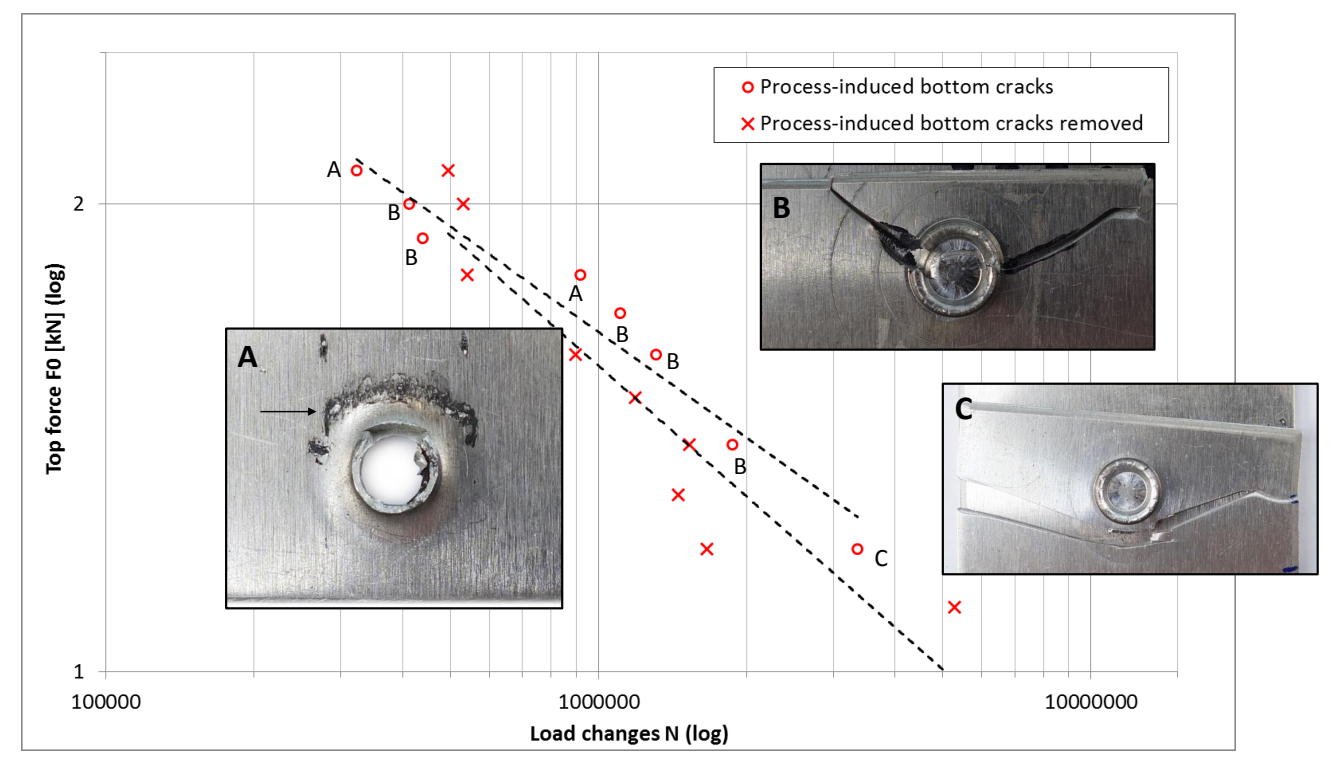

Figure 14: Fatigue test and failure modes

observed difference in Fig.14 could potentially be attributed to the manipulations required for removing the bottom defects. In summary, it can be concluded that the observed process-induced bottom defects do not have a detrimental effect with respect to the fatigue life of the joint loaded in single shear lap configuration.

\section{Conclusion}

Materials with limited ductility are prone to process-induced clinch forming defects. The study focuses on so-called bottom defects which arise due to the high tensile stresses generated when the material is expelled outwards to create the permanent interlock. It is shown that the observed bottom cracks can be predicted with the aid of an axisymmeyric FE model using the Modified Rousselier model provided that the model is inversely calibrated 


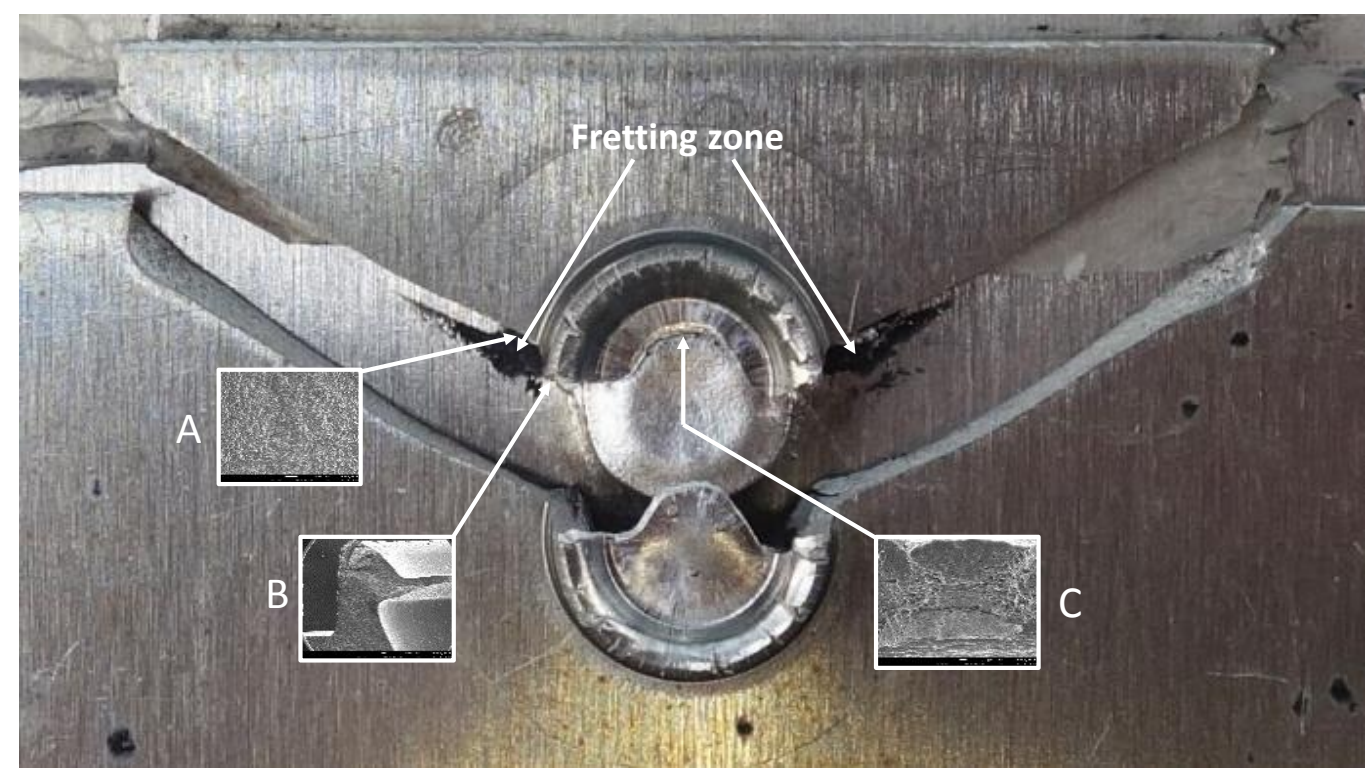

Figure 15: Combined failure mode - Locations SEM analysis and fretting wear

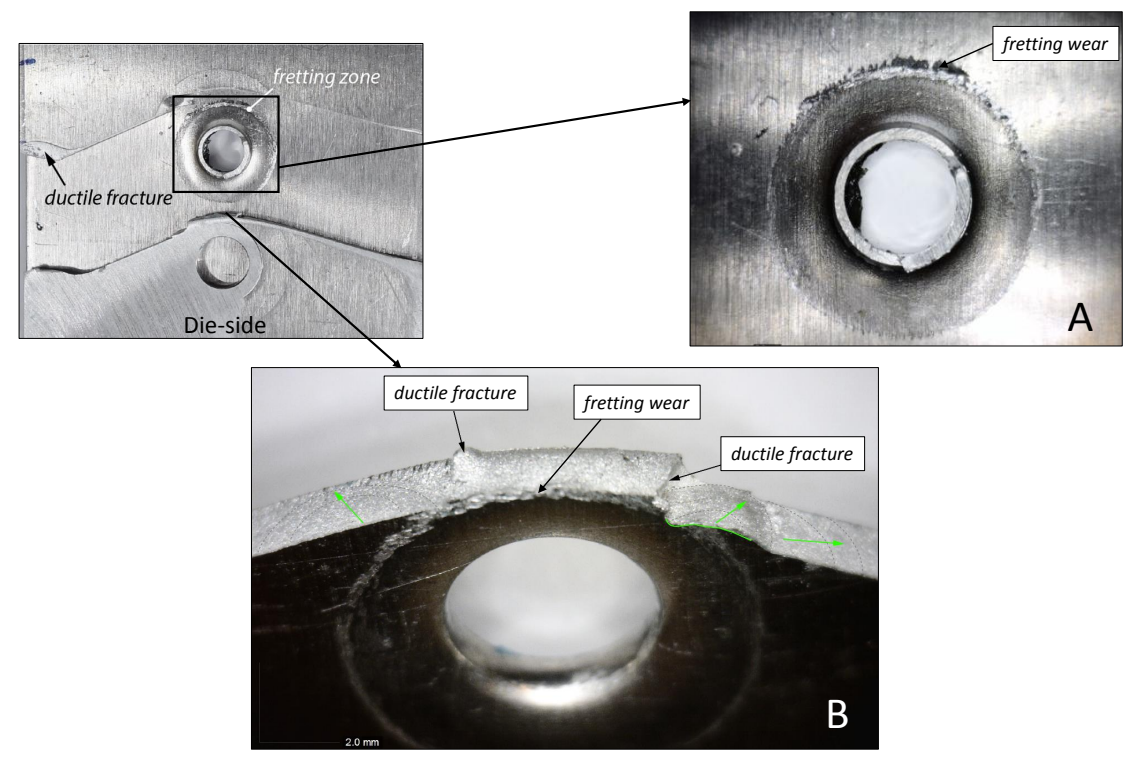

Figure 16: Failure mode C, see Figure 15. Inspection of contacting surfaces (bottom at die-side sheet removed by grinding). Panel A: fretting wear at punch-side sheet. Panel B: fretting wear and ductile fracture at die-side sheet. 


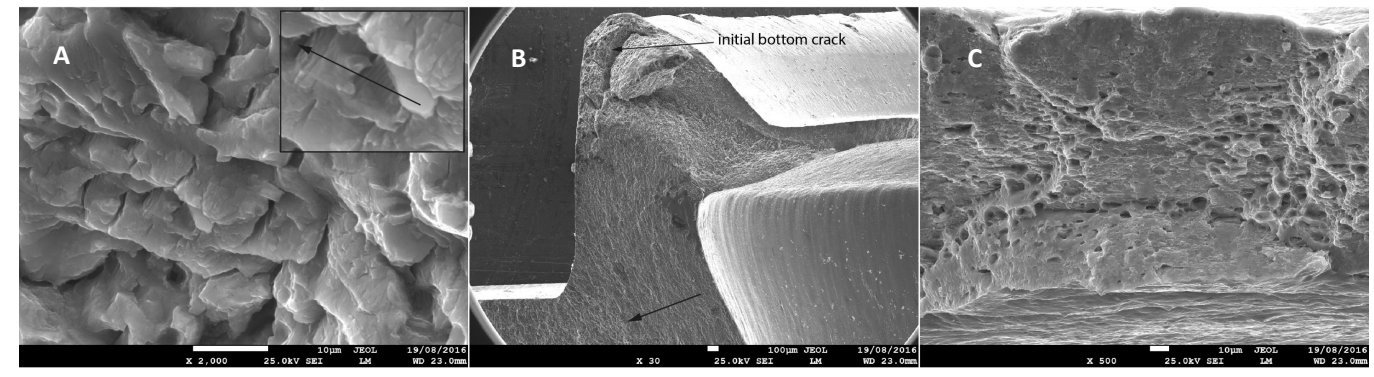

Figure 17: SEM analysis at location A, B and C, see Fig.15

on the basis of experimental observations during the clinch forming process. Future work should focus on the validation of these findings for other material combinations and clinching tools. Furthermore, it is shown that the post-necking strain hardening behavior of the base materials plays an important role in simulating the static single shear lap test. The observed process-induced defects did not have a detrimental effect on single shear lap specimens loaded under quasi-static and cyclic conditions. Fatigue testing of single lap shear specimens revealed three failure modes: neck fracture, combined neck fracture/base material and failure of the base material. All failure modes exhibited fretting wear suggesting that fatigue cracks initiate due to fretting. No experimental evidence was found that fatigue cracks in single shear lap specimens initiate at the observed process-induced bottom defects. To ensure the structural integrity, however, additional research is 
required to understand the effect of cracks under other (multi-axial) static and cyclic loading conditions.

\section{Acknowledgements}

The presented results are part of the CORNET research project Mechanical Joining of Materials with limited Ductility funded by the program for Industrial Research (IGF) of the Federal Ministry of Economics and Technology Germany and the Belgian government agency Flanders Innovation \& Entrepreneurship (VLAIO).

\section{References}

[1] M. Rodriguez-Millán, A. Vaz-Romero, A. Rusinek, J. RodriguezMartinez, A. Arias, Experimental study on the perforation process of 5754-H111 and 6082-T6 aluminium plates subjected to normal impact by conical, hemispherical and blunt projectiles, Experimental Mechanics 54 (2014) 729-742.

[2] S. Coppieters, Experimental and numerical study of clinched connections, Ph.D. thesis, KU Leuven, Belgium (2012).

[3] R. Hörhold, M. Müller, M. Merklein, M. G, Mechanical properties of an innovative shear-clinching technology for ultra-high-strength steel and aluminum in lightweight car body structures, Weld World 60 (2016) 613-620.

[4] J. Mucha, The analysis of rectangular clinching joint in the shearing test, Maintenance and reliability 51 (2011) 45-50. 
[5] Steel RTD Technical Group TGS, Steel products and applications for building, construction and industry, novel joining systems for the automated production of light gauge steel elements, Tech. rep., ECSC Project 7210-PR-252, Ed. Tapino Leino (2003).

[6] F. Lambiase, A. Di Ilio, Damage analysis in mechanical clinching: experimental and numerical study, Journal of Materials Processing Technology 230 (2016) 109-120.

[7] H. Krztoǹ, J. Mucha, W. Witkowski, The application of laboratory x-ray micro-diffraction to study the effects of clinching process in steel sheets, in: Proceedings of the XXIII Conference on Applied Crystallography, Vol. 130, ACTA PHYSICA POLONICA, 2016.

[8] J. Gibmeier, N. Rode, R. Lin Peng, M. Od en, B. Scholtes, Residual stress in clinched joints of metals, Applied Physics A 74 (2002) 14401442 .

[9] J. P. Varis, A novel procedure for establishing clinching parameters for high strength steel, Ph.D. thesis, Lappeenranta University of Technology (2000).

[10] J. P. Varis, Clinching of zinc-coated high strength structural steel (in finnish), Master's thesis, Lappeenranta University of Technology, Department of Mechanical Engineering, Lappeenranta, Finland (1998).

[11] DVS/EFB-merkblatt clinchen-überblick (in german) (2012).

[12] https://www.grantadesign.com (2017). 
[13] O. Hahn, Y. Tan, M. Schoeder, M. Horstmann, Thermally supported mechanical joining of magnesium components, Materials Science Forum 488-489 (2005) 365-370.

[14] S. Höbner, Clinchen moderner blechwerkstoffe, Ph.D. thesis, University Hannover (2005).

[15] X. He, H. Zhang, B. Xing, F. Gu, A. Ball, Mechanical properties of extensible die clinched joints in titanium sheet materials, Materials \& Design 71 (2015) 26-35.

[16] Y. Zhang, X. He, K. Zeng, L. Lei, F. Gu, A. Ball, Influence of heat treatment on mechanical properties of clinched joints in titanium alloy sheets, International Journal of Advanced Manufacturing Technologydoi:DOI 10.1007/S00170-017-0019-5.

[17] F. Lambiase, Clinch joining of heat-treatable aluminum aa6082-t6 alloys under warm conditions, Journal of Materials Processing Technology.

[18] A. A. de Paula, M. T. P. Aguillar, A. E. M. Pertence, P. R. Cetlin, Finite element simulations of the clinch joining of metallic sheets, Journal of Materials Processing Technology 182 (2007) 352-357.

[19] J. Mucha, The analysis of lock forming mechanism in the clinching joint, Materials \& Design 32 (2011) 4943-4954.

[20] S. Coppieters, P. Lava, R. Van Hecke, S. Cooreman, H. Sol, D. Debruyne, P. Van Houtte, Numerical and experimental study of the multi-axial quasi-static strength of clinched connections., International Journal of Material Forming 6 (4) (2013) 437-451. 
[21] F. Xu, S. D. Zhao, X. L. Han, Use of a modified gurson model for the failure behavior of the clinche joint om al6061 sheet, Fatigue \& Fracture of Engineering Materials \& Structures 37 (2014) 335-348.

[22] E. Roux, P. O. Bouchard, Kriging metamodel global optimization of clinching joining processes accounting for ductile damage, Journal of Materials Processing Technology 213 (2013) 1038-1047.

[23] M. Jomâa, Simulation numerique des procedes de clinchage et de rivetage pour application automobile, Ph.D. thesis, Université Pierre et Marie Curie, France. (2007).

[24] S. D. Zhao, F. Xu, J. H. Guo, X. L. Han, Experimental and numerical research for the failure behaviour of the clinched joint using modified rousselier model, Journal of Materials Procesing Technology 214 (2014) 2134-2145.

[25] R. Neugebauer, C. Kraus, S. Dietrich, Advances in mechanical joining of magnesium, CIRP Annals-Manufacturing Technology 57 (2008) 283286.

[26] Y. Abe, T. Kato, K. Mori, Joining of high strength steel and aluminum alloy sheets by mechanical clinching with dies for control of metal flow, Journal of Materials Processing Technology 212 (2012) 884-889.

[27] B. A. Behrens, A. Bouguecha, M. Vucetic, S. Höbner, D. Yilkiran, Y. Jin, I. Peshekhodov, FEA-based optimisation of a clinching process with a closed single-part die aimed at damage minimisation in 
cr240bh-alsi10mnmg joints, Key Engineering Materials 651-653 (2015) $1487-1492$.

[28] F. Lambiase, A. Di Ilio, A. Paoletti, Joining of aluminum alloys with reduced ductility by mechanical clinching, International journal of advanced manufacturing technology 77 (2015) 1265-1304.

[29] M. Carboni, S. Beretta, M. Monno, Fatigue behaviour of tensile -shear loaded clinched joints, Engineering Fracture Mechanics 73 (2006) 178190.

[30] K. Mori, Y. Abe, T. Kato, Mechanism of superiority of fatigue strength for aluminum alloy sheet joined by mechanical clinching and self-pierce riveting, Journal of Materials Processing Technology 212 (2012) 19001905.

[31] Z.-M. Su, P.-C. Lin, W.-J. Lai, J. Pan, Fatigue analysis of self-piercing rivets and clinch joints in lap-shear specimens of aluminum sheets, International Journal of Fatigue 72 (2015) 53-65.

[32] D. Steglich, X. Xian, J. Bohlen, T. Kuwabara, Mechanical testing of thin sheet magnesium alloys in biaxial tension and uniaxial compression, Experimental Mechanics 54 (2014) 1247-1258.

[33] S. Coppieters, S. Cooreman, H. Sol, P. Van Houtte, D. Debruyne, Identification of the post-necking hardening behaviour of sheet metal by comparison of the internal and external work in the necking zone, Journal of Materials Processing Technology 211 (3) (2011) 545-552. 
[34] S. Coppieters, T. Kuwabara, Identification of post-necking hardening phenomena in ductile sheet metal, Experimental Mechanics 54 (2014) $1355-1371$.

[35] http://matchidmbc.be/.

[36] Z. Xue, M. G. Pontin, F. W. Zok, J. W. Hutchinson, Calibration procedures for a computational model of ductile fracture, Engineering Fracture Mechanics 77 (2010) 492-509.

[37] M. G. Cockroft, D. J. Latham, Ductility and workability of metals, Journal of the Institute of Metals 96 (1968) 33-39.

[38] J. R. Rice, D. M. Tracey, On the ductile enlargement of voids in triaxial stress fields, Journal of the Mechanics and Physics of Solids O 17 (1969) 201-2017.

[39] J. Guo, S. Zhao, R. Murakami, S. Zang, Experimental and numerical investigation for ductile fracture of Al-alloy 5052 using modified rousselier model, Computational Material Science 71 (2013) 115-123.

[40] A. Breda, S. Coppieters, D. Debruyne, Equivalent modelling strategy for a clinched joint using a simple calibration method, Thin-Walled Structures 113 (2017) 1-12.

[41] S. Saberi, N. Enzinger, R. Vallant, H. Cerjak, J. Hinterdorfer, R. Rauch, Influence of plastic anisotropy on the mechanical behaviour of clinched joint of different coated thin steel, International Journal of Materials Forming Suppl. 1 (2008) 273-276. 
[42] J. Varis, J. Lepisto, The suitablity of round clinching for high-strength structural steel, Thin-Walled Structures 40 (2002) 225-238.

[43] N. Nong, O. Keju, Z. Yu, Q. Zhiyuan, T. Changcheng, L. Feipeng, Research on press joining technology for automotive metallic sheets, Journal of Materials Processing Technology 137 (2003) 159-163.

[44] DVS/EFB 3480-1 pröfung von verbindungseigenschaften - pröfung der eigenschaften mechanisch und kombiniert mittels kleben gefertigter verbindungen (in german). 